\title{
Utilization of Hydrocarbons by Cladosporium resinae
}

\author{
By L. COFONE, Jun., J. D. WALKER* AND J. J. COONEY \\ Department of Biology, University of Dayton, Dayton, Ohio 45469, U.S.A.
}

(Received 27 March 1972; revised I2 January 1973)

Cladosporium resinae has been isolated from soil and air samples taken over a wide area in Africa, Australia and Europe (Parbery, 1969) and from fresh, estuarine and marine waters (Ahearn \& Meyers, 1972). The organism's biology and its potential for causing malfunctions in aircraft jet fuel systems were reviewed recently by Parbery (I97I). A strain of $C$. resinae examined in our laboratory grows in deep culture on $C_{10}$ to $C_{14} n$-alkanes (Cooney \& Proby, I97I). Other strains grow on $\mathrm{C}_{9}$ to $\mathrm{C}_{18}$ alkanes (Tanaka, Shimizu \& Fukui, I968; Iizuka, Lin \& Iida, I970; Parbery, 1970). Since $C$. resinae is widely distributed in hydrocarbon-rich and in hydrocarbon-poor environments, and since it may have the potential to degrade hydrocarbons which are refractory to other biological agents, it was of interest to determine the range of hydrocarbons which $C$. resinae could use as sole source of energy and of organic carbon.

\section{METHODS AND RESULTS}

Two strains of Cladosporium resinae were used which had been isolated from jet fuel systems. They are coded UD- 42 and UD-43 in our collection. Cultures have been deposited with the American Type Culture Collection, where they bear the accession numbers ATCC 227II and 227I 2 respectively.

Glucose or solid hydrocarbon $(\mathrm{I} \cdot \mathrm{O} \mathrm{g})$ was added to $\mathrm{I} 00 \mathrm{ml}$ of the salts medium of Bushnell \& Haas (I94I) in a $250 \mathrm{ml}$ flask and the mixture was sterilized by autoclaving. Liquid hydrocarbons were filter-sterilized and $\mathrm{I} 0 \mathrm{ml}$ quantities were used as an overlay for $100 \mathrm{ml}$ of sterile salts solution. The $\mathrm{pH}$ was adjusted to $6 \cdot 0$ after addition of carbon source. Hydrocarbons were the highest quality available from commercial sources. Actively growing cells for inoculum were taken from Sabourand Dextrose Broth and washed three times. Cultures were incubated at $28^{\circ} \mathrm{C}$ without shaking.

To test gaseous hydrocarbons, the fungus was streaked on salts solidified with Ion Agar (Colab Laboratories, Chicago, Illinois, U.S.A.). Plates were incubated in a mixture of air and gas from municipal taps. The mixture was renewed thrice daily. The gas consisted of methane, 93; ethane, $3 ; \mathrm{CO}_{2}, \mathrm{I} \cdot 2$; and $\mathrm{C}_{3}$ to $\mathrm{C}_{5}$ alkanes, each less than $\mathrm{I}$ mole $\%$.

After 34 days fungal cells were harvested from cultures which showed growth and the $\mathrm{pH}$ of the aqueous phase was determined. Cultures which did not show evidence of growth were incubated for an additional 23 days. Cells were harvested by filtration on tared filter paper, removing residual salts and hydrocarbon by washing with petroleum ether, hexane and then methanol, then dried to constant weight at $95^{\circ} \mathrm{C}$.

$Q_{\mathrm{O}_{2}}$ values were determined using a Model 53 Biological Oxygen Monitor (Yellow Springs Instrument Co., Yellow Springs, Ohio, U.S.A.) which was standardized using xanthine oxidase (Billiar, Knappenberger \& Little, I970). Hydrocarbons (I0\%, v/v) were

* Present address: Department of Microbiology, University of Maryland, College Park, Maryland, 70742, U.S.A. 
Table I. Growth of Cladosporium resinae (UD-42) on glucose and on hydrocarbons as sole carbon source

\begin{tabular}{|c|c|c|}
\hline rbon sourc & $\begin{array}{l}\text { Growth first } \\
\text { observed at } \\
\text { (days) }\end{array}$ & $\begin{array}{l}\text { Growth (mg } \\
\text { dried cells/ } \\
\text { I00 ml)* }\end{array}$ \\
\hline
\end{tabular}

Carbohydrate

Glucose

$\begin{array}{rrr}3 & 150 & 5 \cdot 3 \\ 22 & & \\ 17 & 3 & 5 \cdot 7 \\ 17 & 17 & 5 \cdot 3 \\ 12 & 19 & 5 \cdot 6 \\ 4 & 68 & 5 \cdot 2 \\ 4 & 97 & 2 \cdot 7 \\ 8 & 132 & 2 \cdot 5 \\ 8 & 105 & 3 \cdot 0 \\ 8 & 57 & 3 \cdot 1 \\ 4 & 45 & 3 \cdot 2 \\ 8 & 66 & 3 \cdot 0 \\ 17 & 57 & 3 \cdot 4 \\ - & 44 & 3 \cdot 4 \\ & - & -\end{array}$

Alkanes

Hexane

Heptane

Octane

Nonane

Decane

Undecane

Dodecane

Tridecane

Tetradecane

Pentadecane

Hexadecane

Nonadecane

Paraffin oil

-

Alkenes

Hexene-I*

Octene-I *

Decene-I

Dodecene-I

Tetradecene-7

observed at dried cells/

of harvest*

Branched alkanes

2-methyl undecane

2,6, I I-trimethyl dodecane*

Cyclic hydrocarbons

Cyclohexane

Cyclohexene

$\overline{48}$

48
17

12

14

Aromatic

Benzene

$m$-Toluic acid*

$p$-Toluic acid*

Benzoic acid*

Catechol*

Salicyclic acid*

DL-Mandelic acid*

Toluene

$o$-Xylene

$m$-Xylene

p-Xylene*

Isopropylbenzene

Phenol*

Naphthalene*

Anthracene*

Phenanthrene*

25

8

25

22

二

二

$\overline{-}$

22

22

22

-

22

-

=
$5 \cdot 6$

$5 \cdot 4$

$5 \cdot 5$

$5 \cdot 4$

$4 \quad 5 \cdot 4$

二

$-$

$-$

=

$5 \quad 5.5$

$5 \quad 53$

- 5.7

$-\quad 5$

$\quad$ -

* Cultures were normally harvested after 34 days of incubation. Those cultures in which growth was not evident at 34 days were allowed to incubate for a total of 57 days; such cultures are noted in the Table by an asterisk (*). 
tested as emulsions prepared in Bushnell-Haas salts by subjecting the mixture to ultrasound. Pesticides were added as solution in acetone.

Data are presented for strain UD-42. Strain UD-43 gave similar results except as noted. Values for growth are averages from at least two experiments, and growth yields from replicate flasks did not vary more than $10 \%$.

$n$-Alkanes from $\mathrm{C}_{9}$ through $\mathrm{C}_{19}$ gave moderate to high dry-weight yields. Growth was slower on alkanes than on glucose, but dry-weight yields of UD-42 on $n$-undecane and of UD-43 on $n$-nonane, $n$-decane, and $n$-dodecane approached the yields obtained on glucose (Table I). Growth on $n$-alkanes was accompanied by a decrease in $\mathrm{pH}$ which correlated with cell dry-weight yields. At either end of the $n$-alkane series growth decreased, and no growth was observed on gaseous hydrocarbons or on paraffin oil, which contained $n$-alkanes from $\mathrm{C}_{29}$ to $\mathrm{C}_{34}$.

A number of strains of Cladosporium resinae grow on $\mathrm{C}_{9}$ to $\mathrm{C}_{18} n$-alkanes (Tanaka et al. I968; Iizuka et al. 1970; Parbery, I970). But some isolates vary widely in their ability to use n-alkanes; Markovetz, Cazin \& Allen (1968) observed only limited growth of Cladosporium sp. on $\mathrm{C}_{10}, \mathrm{C}_{14}$ and $\mathrm{C}_{16}$, and no growth on $\mathrm{C}_{12}$. Cooney \& Proby (I97I) reported that in deep culture strain UD-42 did not yield good growth on $\mathrm{C}_{12}$ as compared to shorter- or longer-chain hydrocarbons. We have observed that shaken flasks give higher growth yields than static cultures on some hydrocarbons and lower yields on others. Thus, growth yields vary with the strain, the hydrocarbon, and with growth conditions. The $\mathrm{pH}$ value was lower in static cultures than in shaken cultures, indicating that culture conditions can also affect production and/or utilization of extracellular acids. Those cultures which had a low $\mathrm{pH}$ value $\left(3^{\circ}\right)$ had very dark mycelial mats. The intracellular pigments are presumably melanins, but they have not been studied.

Growth was slower and less extensive on alkenes than on the corresponding alkanes (Table I). The location of the double bond in the centre of tetradecene may allow for diterminal oxidation by providing two saturated ends. Cladosporium resinae grew on a branched alkane with an isopropyl group at one end, but not on an alkane with branching at each end. These observations suggest that in order to serve as a growth substrate, at least one end of an $n$-alkane must be saturated and free of methyl branching.

Each strain grew on benzene, but UD-43 did not grow on the more saturated compounds, cyclohexane or cyclohexene. Addition of a methyl group to benzene, as in toluene, or two methyl groups, as in $o$-xylene did not prevent utilization. But no growth was observed in 57 days when a second methyl group was present in the para position. Growth on isopropylbenzene (cumene) was equivalent to that obtained on benzene, suggesting that the isopropyl side-chain does not inhibit metabolism of the benzene ring and that the side-chain is not preferentially metabolized. Tanaka et al. (I968) reported that an isolate of Cladosporium resinae did not grow on benzene, toluene or xylene. However, the cultures were only incubated for I 4 days, while in the present work growth was first noted after 22 to 25 days. Parbery (1970) noted that different isolates of $C$. resinae varied considerably in length of lag phase on hydrocarbon substrates; in some cases, the lag was as long as 60 days. Addition of hydroxyl or carboxyl functions resulted in molecules which did not support growth. Although benzene was utilized, growth was not observed on the polynuclear aromatic compounds tested. Failure to grow on a particular substrate may be due to lack of the appropriate enzymes or to impermeability. Permeability is suggested in the case of catechol, a proposed intermediate in metabolism of benzene, which supported growth of both strains.

Strain UD-42 did not grow with aldrin, dieldrin, DDT, diazonin, malathion or rotenone as carbon source. None of the pesticides inhibited growth on glucose or on hexadecane and at 
concentrations as high as 20000 p.p.m. aldrin and malathion enhanced growth on hexadecane; and aldrin, dieldrin, DDT, and malathion enhanced growth on glucose. In natural waters pesticides rarely exceed 2 p.p.m. (Dalton, Hodkinson \& Smith, 1970), but they can be concentrated in surface oil slicks (Seba \& Corcoran, 1969). This may have ecological significance since Cladosporium resinae is not only a major member of the aquatic microflora, but it is enriched in oil-polluted waters (Ahearn \& Myers, 1972).

When fungal cells which were actively growing on glucose were washed and transferred to salts solution they had a high endogenous rate of oxygen consumption: $Q_{\mathrm{O}_{2}}\left(\mu 1 \mathrm{O}_{2}\right.$ consumed/mg dry $\mathrm{wt} / \mathrm{h}$ ) of $\mathrm{I} 9$. Washed cells oxidized hexadecane more rapidly than glucose $\left(Q_{\mathrm{O}_{2}}\right.$ corrected for endogenous $=98$ and 6 , respectively), while hexane depressed oxygen uptake (corrected $Q_{\mathrm{O}_{2}}=-\mathrm{I}$ ). The rates of release of ${ }^{14} \mathrm{CO}_{2}$ from labelled cells indicated that hexane decreased endogenous respiration, but hexadecane and glucose did not alter the rate of endogenous respiration. None of the pesticides affected oxygen uptake on glucose or hexadecane.

Jones \& Edington (1968) reported that hydrocarbons can accumulate in a zone in the soil. Parbery (1969) demonstrated that various strains of Cladosporium resinae grow on vegetable oils, leaf waxes, keratin and chitin. He also showed that $C$. resinae does not compete actively with other organisms. The ability to use a variety of hydrocarbons in the absence of organic nitrogen indicated by the present work, coupled with ability to grow on substrates which are recalcitrant to attack by many other organisms and in the presence of pesticides, is consistent with the view that $C$. resinae can proliferate in ecological niches which cannot be occupied by other organisms.

\section{REFERENCES}

Ahearn, D. G. \& Meyers, S. P. (1972). The role of fungi in the decomposition of hydrocarbons in the marine environment. In Biodeterioration of Materials, pp. 12-18. Applied Science Publishers.

Billiar, R. B., Knappenberger, M. \& Little, B. (1970). Xanthine oxidase for calibration of the oxygen electrode apparatus. Analytical Biochemistry 36, IOI-104.

Bushnell, L. D. \& HAAS, H. F. (I94I). The utilization of certain hydrocarbons by microorganisms. Journal of Bacteriology 4I, 653-673.

Cooney, J. J. \& Proby, C. M. (1971). Fatty acid composition of Cladosporium resinae grown on glucose and on hydrocarbons. Journal of Bacteriology 108, 777-781.

Dalton, S. A., Hodkinson, M. \& SMrth, K. A. (1970). Interactions between DDT and river fungi. I. Effects of p,p'-DDT on growth of aquatic hyphomycetes. Applied Microbiology 20, 662-666.

IIzUKA, H., LiN, H. T. \& IIDA, M. (1970). Ester formation from $n$-alkanes by fungi isolated from aircraft fuel. Zeitschrift für allgemeine Mikrobiologie 1o, 189-196.

Jones, J. G. \& Edington, M. A. (1968). An ecological survey of hydrocarbon-oxidizing micro-organisms. Journal of General Microbiology 52, 38I-390.

Markovetz, A. J., Cazin, J. \& Allen, J. E. (I968). Assimilation of alkanes and alkenes by fungi. Applied Microbiology 16, 487-489.

Parbery, D. G. (1969). The natural occurrence of Cladosporium resinae. Transactions of the British Mycological Society 53, 15-23.

PARBery, D. G. (1970). The kerosene fungus, Amorphotheca resinae; its biology, taxonomy and control. $\mathrm{Ph} . \mathrm{D}$. Thesis, University of Melbourne, Australia.

Parbery, D. G. (I97I). Biological problems in jet aviation fuel and the biology of Amorphotheca resinae. Material and Organism 6, 16I-208.

Seba, D. B. \& Corcoran, E. F. (1969). Surface slicks as concentrators of pesticides in the marine environment. Pesticides Monitoring Journal 3, 190-193.

TanakA, A., Schimizu, S. \& FuKui, S. (1968). Studies on the utilization of hydrocarbons by microorganisms. IV. Growth of molds on hydrocarbons. Journal of Fermentation Technology 46, 46I-467. 